\title{
HEALTH OF MOTHERS OF CHILDREN WITH INTELLECTUAL DISABILITY OR AUTISM SPECTRUM DISORDER: A REVIEW OF THE LITERATURE
}

\author{
Jenny Fairthorne, Nick de Klerk, Helen Leonard
}

\begin{abstract}
Background: The deficits associated with intellectual disability (ID) and autism spectrum disorder (ASD) place a burden on their co-residing families which may impact maternal health.
\end{abstract}

Objectives: We aimed to compare the health of mothers of children with ID or ASD to that of other mothers and to each other, according to the disability subgroup of their child.

Methods: Due to the broad scope of articles in our chosen area, we searched data-bases multiple times, each time using a different combination of search terms related to ID and ASD, carers and health. Papers were retained which met six criteria and were then sorted into two groups. Firstly, we grouped all papers which compared the health of mothers of children with ID or ASD to other mothers. Secondly, we grouped papers which compared maternal health by the subgroup of the child's disability.

Results: We retained 60 papers. Researchers consistently identified poorer health in the mothers of children with ID or ASD. Further, the research suggested that mothers of children with Down syndrome had the least impaired health and mothers of children with ASD, and particularly ASD without ID, the most impaired health.

Conclusion and implications: Providing more support, such as home services, for mothers of children with ID or ASD and health issues, might make the way for the improved health of these mothers. Importantly, mothers of children with ASD without ID were identified as a group needing special assistance. Further research into the correlates of poorer health in mothers of children with ID or ASD is implicated so that more informed supports and interventions can be developed to assist these mothers.

\section{Conflict of Interest:}

All authors report that there is no conflict of interest.

Key words: Health, mothers, disability, autism, Down, Asperger, parents, psychiatric 


\section{INTRODUCTION}

A diagnosis of intellectual disability (ID) requires an IQ of less than 70 along with deficits in adaptive functioning which have been present prior to the age of 18 years (American Psychiatric Association 2013). The deficits associated with the debilitating neurodevelopmental condition, autism spectrum disorder (ASD) are present from early childhood. These deficits severely impact functioning in the areas of sociability and behaviour. Researchers have demonstrated poorer mental health (Singhi et al. 1990, Piven et al. 1991) physical health (Eisenhower, Blacher, and Baker 2013, Cantwell, Muldoon, and Gallagher 2014) and a lower quality of life (Browne and Bramston 1996, Mugno et al. 2007) in the mothers of children with ID or ASD. These mothers face many more challenges in the rearing of their children. For example, they may face increased expenditure in terms of medication, doctors' fees and child-care while been less able to be employed than other mothers. Other challenges experienced by these women include more self-perceived stigma (Werner and Shulman 2014, Kelso, French, and Fernandez 2005) and less informal and family support (Caldwell 2008, McStay, Trembath, and Dissanayake 2014). On the other hand, some researchers have suggested that the poorer mental health of mothers of children with ASD associated with an increased genetic liability to psychiatric disorders (Piven et al. 1991). However, we found no research which integrated the existing research investigating or comparing the health of mothers of children with ID or ASD to mothers of children without these disorders. In addition, we found no paper which provided a comparison of the health of mothers of children with Down syndrome, other forms of ID and ASD according to the presence or absence of ID. This is important because the identification of particularly vulnerable groups would enable supports and interventions to be aimed at improving the health and quality of life of these vulnerable mothers. In order to compare and rank the evidence provided by research papers in this area, we need to objectively assess the strength of evidence provided by each. Therefore, in this review, we had three primary aims. Firstly, we aimed to use existing research to compare the health and quality of life of mothers of children with ID or ASD to that of mothers of children without these conditions. Secondly, we aimed to compare the health of mothers of children with ID or ASD according to the subgroup of their disability. Thirdly, we aimed to objectively to assess the strength of evidence of the papers included in our review.

\section{METHODS}

Due to the broad scope of articles in our chosen area, we searched the Medline, Web of Knowledge, Scopus and Google scholar databases multiple times. Each time we used a different combination of search terms related to ID and ASD, mothers and health. The search terms, by group are listed below.

- Terms associated with ID, ASD or diagnostic subgroups of ID or ASD:;

- Terms associated with health: health, depression, physical, mental, psych* phenotype*;

- Terms associated with carers: mothers, parents, care*.

A paper was included in the review if it met the criteria below: 
- It was published online by a peerreviewed journal between 1st January 1990 and 31st December, 2014 inclusive;

- It described original research (and not a review) in English and was a full length paper;

- The underlying research utilised a cohort, case-control, correlation or cross-sectional study

- The study population was more than 20;

- It compared the health of mothers, parents or carers of children with ASD or ID with that of mothers, parents or carers of children without disability or with a population norm;

- It compared the health of mothers, parents or carers of children with a subgroup of ID (such as Down syndrome) or ASD with that of mothers, parents or carers of children with another subtype of ID or ASD.

We chose these selection criteria with care. For example, we excluded papers with study populations of less than 20 because a small sample size reduces the statistical power of a study and with smaller studies, there is a lower probability that a significant result is a true effect (Button et al. 2013). Our choice of 20 as the cut-off was arbitrary. A diagram of the selection process is in Figure 1. We then assessed the strength of the evidence provided by each paper using a six level measure (Table 1).

Table 1: Strength of evidence for studies in the review

\begin{tabular}{c|l|ll}
\hline $\begin{array}{c}\text { Level of } \\
\text { evidence }\end{array}$ & $\begin{array}{l}\text { Designated descriptor of } \\
\text { level of evidence }\end{array}$ & Description of study \\
\hline $\mathbf{5}$ & Strong & Correlational/ descriptive studies & \\
\hline $\mathbf{4}$ & Moderate & $\begin{array}{l}\text { Correlational study with validated scores \& } \\
\text { magnitude of effect assessed }\end{array}$ & \\
\hline $\mathbf{3}$ & Mild & Correlational study with validated scores & \\
\hline $\mathbf{2}$ & Weak & $\begin{array}{l}\text { Correlational study with magnitude of effect } \\
\text { assessed }\end{array}$ \\
\hline $\mathbf{1}$ & Some indication only & Correlational study & \\
\hline $\mathbf{6}$ & & Descriptive studies \\
\hline $\mathbf{4}$ & Moderate & Population studies \\
\hline $\mathbf{3}$ & Mild & Longitudinal design with control & \\
\hline $\mathbf{2}$ & Weak & Cross-section design with control & \\
\hline
\end{tabular}

Table adapted from Description of levels of evidence grades and recommendations(Practicing Chiropractors' Committee on Radiology Protocols 2006) and Evaluating the quality of evidence from correlational research for evidence-based practice(Thompson et al. 2005) Note: 6 provides the highest level of evidence 


\section{RESULTS}

Figure 1: Literature search

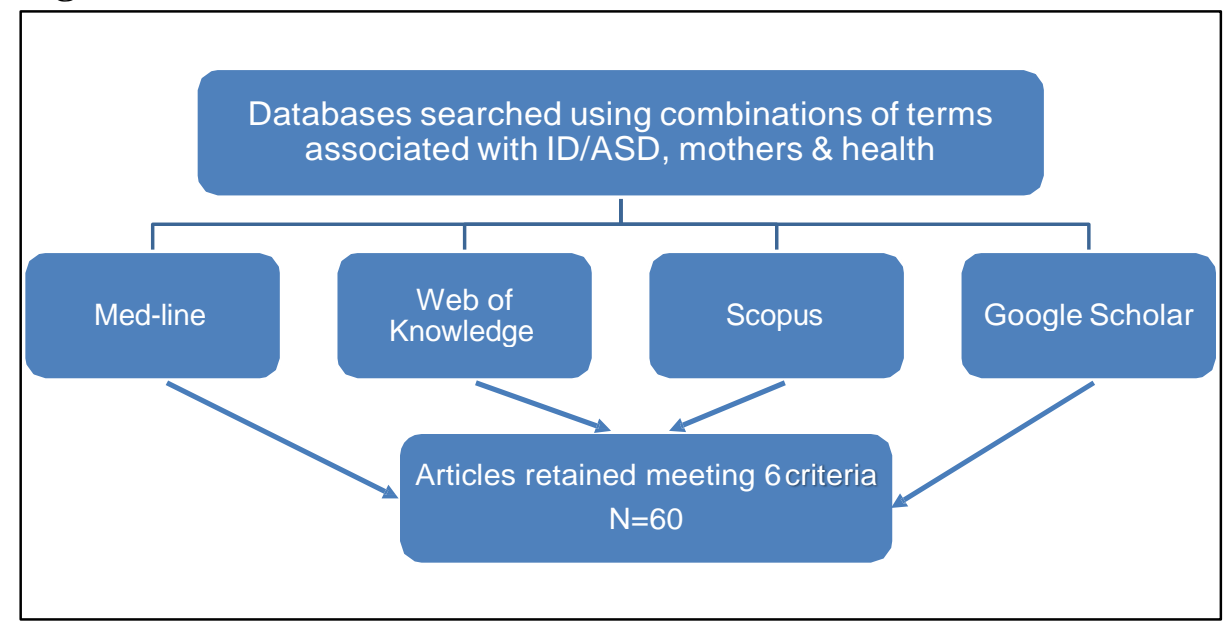

ID, intellectual disability; ASD, Autism spectrum disorder

We retained sixty papers for the review (Figure 1) and acknowledge that searching with different search terms or different combinations of terms may have provided a different basis for our review. Papers were sorted into the two groups of Comparisons with the general population and Comparisons by the child's disability. In Table 2 is a summary of each paper which gives the assessed strength of evidence, methods of data collection and recruitment, the country of origin, the study population and the disability groups compared. 
Table 2: Properties of papers included in the review

\begin{tabular}{|c|c|c|c|c|c|c|}
\hline Study & $\begin{array}{l}\text { Strength of } \\
\text { evidence }\end{array}$ & Data collection & Recruitment & Country & $\begin{array}{l}\text { Study } \\
\text { population }\end{array}$ & Grouping for comparison \\
\hline Allik, Larsson, and Smedje, 2006 & 5 & SF-12 & Service providers & Sweden & 31 cases, 30 controls & ASD no ID, TD \\
\hline Baker-Ericzén et al., 2005 & 4 & 120 -item stress index & Schools & US & 37 cases, 23 controls & ASD with \& without ID \\
\hline Blacher et al., 1997 & 4 & Depression scale & Service providers & US & 101 cases, 148 controls & ID, TD \\
\hline Bolton et al., 1998 & 3 & Questionnaires & Service providers & UK & 99 ASD, 36 DS & ASD, DS \\
\hline Bourke et al., 2008 & 4 & SF-12 & Service providers & Australia & 363 cases & Down, population norms \\
\hline Browne and Bramston, 1998 & 4 & $\begin{array}{l}\text { Stress scale \& QOL } \\
\text { measure }\end{array}$ & Service providers & Australia & 44 cases, 58 controls & ID, TD \\
\hline Caldwell, 2008 & 5 & SF-36 & Service providers & US & 1,400 cases & DD, population norms \\
\hline Cantwell et al., 2014 & 5 & $\begin{array}{l}\text { 4-item stress scale, } \\
\text { PH questionnaire }\end{array}$ & University/other & Ireland & 109 cases, 58 controls & DD, TD \\
\hline Chen et al., 2001 & 5 & SF-36 & Service providers & US & 108 cases & 55-64 years, $\geq 65, \mathrm{ID}$, pop norm \\
\hline Daniels et al., 2008 & 6 & Linked data & Linked data & Sweden & 1,227 cases, 30,693 controls & ASD, TD \\
\hline Dumas et al., 1991 & 3 & Stress/depression indices & Service providers & Canada & $(30,30,30)$ cases, 60 controls & ASD, DS, Behav problems, TD \\
\hline Eisenhower, Baker, and Blacher, 2005 & 3 & $\begin{array}{l}\text { Depression scale, } \\
\text { Family impact scale } \\
\end{array}$ & Service providers & US & $(14,12,43)$ cases, 136 controls & ASD, DS, DD, TD \\
\hline Eisenhower, Baker, and Blacher, 2009 & 5 & 1-item PH scale, & Service providers & US & 218 cases, 127 controls & $\mathrm{DD}, \mathrm{TD}$ \\
\hline Eisenhower, Blacher, and Baker, 2013 & 3 & Single-item measure & Service providers & US & 116cases, 129 controls & TD, DD \\
\hline Emerson, 2003 & 5 & Questionnaires & Larger survey & UK & 245 cases, 9,481 controls & ID, TD \\
\hline Estes et al., 2009 & 3 & Stress \& Distress indices & Service providers & US & $51 \mathrm{ASD}, 22 \mathrm{DD}$ & ASD, DD \\
\hline Fairthorne et al., 2014 & 6 & Linked data & Linked data & Australia & 300,123 & ID or ASD, no ID or ASD \\
\hline Fairthorne et al., 2015a & 6 & Linked data & Linked data & Australia & $\begin{array}{l}(37,728,470,542) \text { cases, } \\
271,249 \text { controls }\end{array}$ & ID not DS, DS, No ID or ASD \\
\hline Fairthorne et al., 2015b & 6 & Linked data & Linked data & Australia & $\begin{array}{l}(1156,542) \text { cases, } 271,249 \\
\text { controls }\end{array}$ & $\begin{array}{l}\text { ASD with ID, ASD without ID, No ID } \\
\text { or ASD }\end{array}$ \\
\hline Gallagher et al., 2009 & 5 & Blood samples & Previous study & UK & 32 cases, 29 controls & DD sub-groups, TD \\
\hline Gallagher and Whiteley, 2013 & 5 & Perceived Stress Scale & Service providers & Ireland & 70 cases, 45 controls & ID, TD \\
\hline Griffith et al., 2010 & 3 & $\begin{array}{l}\text { Stress, depression \& } \\
\text { affect scales }\end{array}$ & Previous study & UK & 19 DS, 19 ASD, 19 ID & DS, ASD, ID \\
\hline Gupta 2007 & 3 & Questionnaire & Previous study & US & 28 cases, 22 controls & DD, TD ( \& others) \\
\hline $\begin{array}{l}\text { Hamlyn-Wright, Draghi-Lorenz, and } \\
\text { Ellis, } 2007\end{array}$ & 3 & Stress index & Service providers & UK & $(265,223)$ cases, 131 controls & ASD, DS, TD \\
\hline Harvey, O'Callaghan, and Vines, 1997 & 4 & Stress scale \& qu'aire & Service providers & Australia & 65 cases, 75 controls & $\mathrm{DD}, \mathrm{TD}$ \\
\hline Hedov, Anneren, and Wikblad, 2000 & 4 & SF-36 & Service providers & Sweden & 207 cases & DS, population norm \\
\hline Jeans et al., 2013 & 3 & Questionnaires & Previous study & US & $\approx 100$ cases $, \approx 11,000$ controls & ASD, TD \\
\hline Jokiranta et al., 2013 & 6 & Linked data & Linked data & Finland & 4,713 cases, 18,852 controls & $\mathrm{AD} / \mathrm{AS} / \mathrm{PDD}(\mathrm{NOS})$, before/after birth \\
\hline Khanna et al., 2011 & 4 & SF-12 \& other scales & Service providers & US & 304 cases & ASD, population norm \\
\hline Lach et al., 2009 & 5 & $\begin{array}{l}\text { 3-item scale \& 12-item } \\
\text { scale }\end{array}$ & Previous study & Canada & $\begin{array}{l}(414,750,1,067) \text { cases, } 7,236 \\
\text { controls }\end{array}$ & Neuro \& Behav combinations, TD \\
\hline Larsson et al., 2005 & 6 & Linked data & Linked data & Denmark & 698 cases, 17,450 controls & ASD, TD, psych. history before diag. \\
\hline Lee et al., 2009 & 3 & Multiple surveys & Service providers & US & 89 cases, 46 controls & HFASD, TD \\
\hline Lenhard et al., 2005 & 3 & Questionnaires & Service providers & Germany & $(411,66)$ cases, 69 controls & DS, ID (unknown cause), TD \\
\hline Llewellyn et al., 2010 & 5 & SF-12 & Service providers & Australia & 64 cases & ID vs population norm \\
\hline Lovell, Moss, and Wetherall, 2012 & 5 & Cortisol levels & Support groups & UK & 56 cases, 22 controls & ASD, ADHD, TD \\
\hline
\end{tabular}


Table 2: Properties of papers included in the review

\begin{tabular}{|c|c|c|c|c|c|c|}
\hline Study & $\begin{array}{l}\text { Strength of } \\
\text { evidence }\end{array}$ & Data collection & Recruitment & Country & $\begin{array}{l}\text { Study } \\
\text { population }\end{array}$ & Grouping for comparison \\
\hline Magaña and Smith, 2006 & 3 & 6-item survey & Previous study & $\overline{\mathrm{US}}$ & 162 cases & DD, population norms \\
\hline Montes and Halterman, 2007 & 3 & 2-item scale & Previous study & US & 364 cases, 61,408 controls & ASD, TD \\
\hline Morgan et al., 2012 & 6 & Linked data & Linked data & Australia & 686 cases, 1,831 controls & Grouped by maternal disorder \\
\hline Mouridsen et al., 2007 & 6 & Linked data & Clinics & Denmark & 115 cases, 330 controls & ASD, TD \\
\hline Mugno, Ruta, D'Arrigo, et al., 2007 & 5 & Validated questionnaire & Service providers & Italy & 115 cases, 42 controls & PDD, ID, TD \\
\hline Norlin and Broberg, 2013 & 3 & $\begin{array}{l}\text { Wellness scale, } \\
\text { stress questionnaire }\end{array}$ & Previous study & Sweden & 58 cases, 178 controls & ID, TD \\
\hline Olsson and Hwang, 2001 & 3 & Depression inventory & Service providers & Sweden & $(145,52)$ cases, 204 controls & ASD, ID without ASD, TD \\
\hline Olsson and Hwang, 2008 & 3 & Postal surveys & Service providers & Sweden & 62 cases, 183 controls & ID, TD \\
\hline Piven et al., 1991 & 3 & Questionnaire & Service providers & US & $42 \mathrm{ASD}, 42 \mathrm{DS}$ & ASD, DS \\
\hline $\begin{array}{l}\text { Rizk, Pizur-Barnekow, and Darragh, } \\
2011\end{array}$ & 4 & SF-12 & Service providers & US & 33 cases & ASD, population norm \\
\hline Sanders and Morgan, 1997 & 3 & Stress \& family indices & Service providers & US & $(18,18)$ cases, 18 controls & ASD, DS, TD \\
\hline Schieve et al., 2011 & 3 & Aggravation scale & Previous study & US & 872 cases, 11,100 controls & Current ASD \& no DD \\
\hline Scott et al., 1997 & 4 & $\begin{array}{l}\text { Depression \& other } \\
\text { scales }\end{array}$ & Service providers & Canada & 108 cases, 188 controls & DS, TD \\
\hline Seltzer et al., 2011 & 5 & $\begin{array}{l}\text { Depression scale, } \\
\text { questionnaire }\end{array}$ & Previous study & US & 220 cases, 1,042 controls & IDD co-residing/non- co-residing, TD \\
\hline Singhi et al., 1990 & 3 & Scales/questionnaire & Service providers & India & 50 cases, 50 controls & ID, TD \\
\hline Smith, Seltzer, and Greenberg, 2012 & 3 & Self-report diary & Previous studies & US & 96 cases, 230 controls & ASD, TD, co-residing \\
\hline Stoneman, 2007 & 3 & Multiple indices & Service providers & US & 29 cases (DS), 21 comparisons & DS, ID of unknown cause \\
\hline Stores et al., 1998 & 3 & Stress index & Service providers & UK & 91 cases, 78 controls & DS, ID not DS, TD \\
\hline Sullivan et al., 2012 & 6 & Linked data & Linked data & Sweden/Israel & $\begin{array}{l}30,800 \text { cases, } \approx 900,000 \\
\text { controls }\end{array}$ & ASD with ID, ASD without ID \\
\hline $\begin{array}{l}\text { Totsika, Hastings, Emerson, Berridge, et } \\
\text { al., } 2011\end{array}$ & 5 & $\begin{array}{l}\text { Validated stress scale, } \\
\text { SF-8 }\end{array}$ & Previous study & UK & $\begin{array}{l}(82,32,412) \text { cases, } 14,444 \\
\text { controls }\end{array}$ & ASD, ASD with ID, ID only \\
\hline $\begin{array}{l}\text { Totsika, Hastings, Emerson, Lancaster, } \\
\text { et al., } 2011\end{array}$ & 3 & $\begin{array}{l}\text { General health } \\
\text { questionnaire }\end{array}$ & Previous study & UK & $\begin{array}{l}(47,51,590) \text { cases, } 17,727 \\
\text { controls }\end{array}$ & ASD, ASD with ID, ID only \\
\hline Veisson, 1999 & 3 & Questionnaires & Service providers & Estonia & 101 cases, 101 controls & Disabled versus Non-disabled \\
\hline Watt and Wagner, 2012 & 3 & $\begin{array}{l}\text { 36-item stress \& } 90- \\
\text { item symptom indices }\end{array}$ & Service providers & Canada & 50 cases, 50 controls & ASD, TD \\
\hline Yamaki, Hsieh, and Heller, 2009 & 3 & 15-item survey & Service providers & US & 206 cases, & IDD, local population norms \\
\hline Zablotsky, Bradshaw, and Stuart, 2013 & 3 & $\begin{array}{l}\text { 1-item health, 3-item } \\
\text { stress indices }\end{array}$ & Previous study & US & 1,114 cases, $\approx 56,000$ controls & ASD, TD \\
\hline
\end{tabular}

ASD, Autism spectrum disorder; DS, Down syndrome ; ID, intellectual disability; SF-36; the Short-Form 36-Item Health Survey; PH, physical health; SF-12, Short Form 12-item survey; Behav problems, Behaviour problems; Psych, Psychiatric disorder; TD, typically developing; DD; Developmental disability; AD, Autistic disorder; AS, Asperger syndrome; PDD(NOS), Pervasive developmental disorder (not otherwise specified); Neuro, neurodevelopmental disorders; behav, behaviour; HFASD, High functioning autism; ADHD, Attention Deficit Hyperactivity Disorder; IDD, intellectual and developmental disability; diag., diagnosis; QOL, Quality of Life; qu'aire, questionnaire. 


\section{DISCUSSION}

Firstly, we discuss the physical and mental health, followed by the overall health and quality of life of the mothers of children with ID or ASD compared to other mothers. Secondly, we summarize the research comparing the health of mothers of children from different diagnostic subgroups of ID and ASD. Finally, we summarize our findings and discuss their implications.
1. HEALTH OF MOTHERS OF CHILDREN WITH ID OR ASD

\subsection{Comparisons with the general} population

In this section, we compare the health of mothers of children with ID or ASD using the three categories of Physical health, Mental health and Overall health and quality of life (Figure 1). Due to the abundance of research on psychiatric disorders with these mothers, we have subdivided Mental health into the subcategories of Psychiatric disorders and Other aspects of mental health.

Figure 1: Sub-categories of health in the mothers of children with ID or ASD ID, Intellectual disability; ASD, Autism spectrum disorder

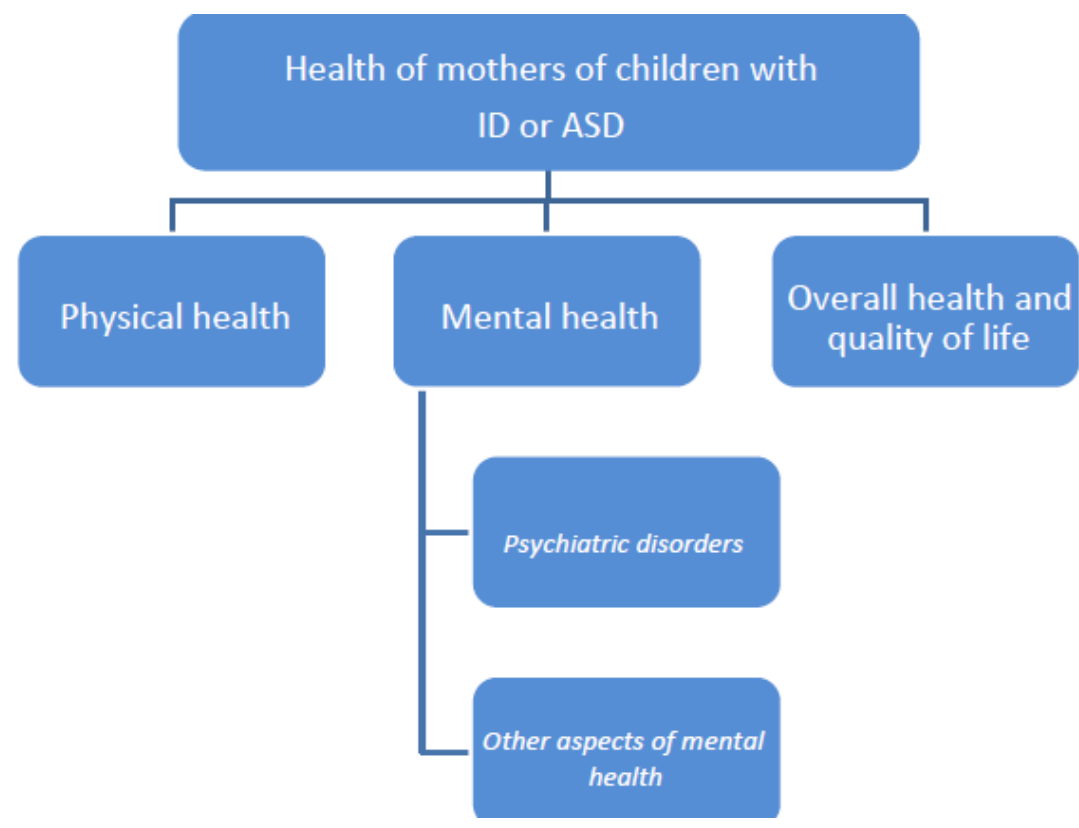

\subsubsection{Physical health}

There is high quality evidence that the mothers and parents of children with ID or ASD have poorer psychical health. A population study of the mortality of mothers of children with developmental disabilities (Fairthorne et al. 2014) provided high-level evidence (Table 1) that these mothers were more likely to die of cancer or cardiovascular disease than other mothers. Strong evidence (Table 1) was provided by four other studies. One of these (Cantwell, Muldoon, and Gallagher 2014) assessed poorer self-reported physical health in parents of children with ID or ASD than controls. In another of the studies (Gallagher et al. 2009), a 
comparison of blood samples, before and after vaccination, revealed that parents of children with ID or ASD had a poorer antibody response than mainstream parents. A third study (Seltzer et al. 2011), used extracted population data and showed that parents living with their adult children with ID or ASD had higher rates of cardiovascular problems than mainstream parents. Finally, carers of children with neurological disorders reported a higher prevalence of asthma, back problems and migraines than carers of children without these problems (Lach et al. 2009). Four research groups provided mild evidence (Table 1) of the poorer physical health of carers of persons with ID or ASD. First, researchers (Eisenhower, Blacher, and Baker 2013) assessed poorer physical health in mothers using item-based scales. By way of surveys, older caregivers of persons with ID or ASD reported an increased prevalence of arthritis compared to older caregivers in the general population (Magaña and Smith 2006, Yamaki, Hsieh, and Heller 2009). Moreover, the second of these studies (Yamaki, Hsieh, and Heller 2009) also identified excesses of high blood pressure, obesity and limited mobility in carers who were over 40 years and a higher prevalence of diabetes and high blood cholesterol in 40 to 59 year olds carers compared to age matched controls.

There is also high quality evidence of the poorer physical health of the mothers and parents of children with ID. Three studies produced strong evidence (Table 1) of impaired physical health. For example, carers who lived with their child with ID reported more headaches, sleep disturbances, gastro-intestinal problems and respiratory infections than controls (Gallagher and Whiteley 2013). Other parents, co-residing with their child with ID or developmental disability, had a higher average Body Mass Index (BMI) than similar parents who were not coresiding. Mothers of three year olds with developmental delay without ASD assessed their physical health as poorer than did mothers of other three year olds (Eisenhower, Baker, and Blacher 2009). Likewise, during interview, parents of children with ID reported poorer physical health and more frequent visits to their family doctor than the control group (Gallagher and Whiteley 2013).

There is also strong evidence (Table 1) of lower levels of self-reported physical health (Mugno et al. 2007) and more episodes of physical illness (Lovell, Moss, and Wetherall 2012) in the parents of children with ASD compared to the parents of children without disabilities. Using the Short-Form 12-Item Health Survey (SF-12), mothers (Allik, Larsson, and Smedje 2006) of children with ASD without ID reported poorer physical health than population norms. Comparable results, but at a lower level of evidence (Table 1), were also described (Smith, Seltzer, and Greenberg 2012) with mothers of adolescents with ASD reporting have more headaches, backaches, muscle soreness, tiredness and hot flushes than mothers of adolescents with no ASD.

Studies with null findings are more scant with only three studies providing strong evidence (Table 1) that there is no detectable difference in the physical health of carers of children with ID or ASD and the carers of typically developing children. One such study (Chen et al. 2001) used the Short-Form 36-Item Health Survey (SF36) and surveyed the health of middle-aged and older mothers of adults with ID. Another (Llewellyn et al. 2010) compared 
older parent/carers of adults with ID to that of their counterparts in the general population. In the final study, mothers provided information at interviews conducted in the each of the four countries of the UK. The researchers deemed that the physical health limitations of the 526 case mothers of children with ID or ASD were not greater than that of the 14,444 mothers of typically developing children (Totsika, Hastings, Emerson, Berridge, et al. 2011) This might be because this comparison was made after controlling for mental health. In addition, children were only five years old and mothers would not have had longer term exposure to the challenges of their children.

\subsubsection{Mental health Psychiatric disorders}

Only two studies were found which explored the psychiatric health of mothers of children with ID using linked health data. In contrast, the poorer psychiatric health of mothers of children with ASD has been demonstrated in six studies over the last ten tears. Studies using linked health data provide a high level of evidence (Table 1) of the poorer psychiatric health of mothers of children with ID or ASD. The first of the studies of mothers of children with ID identified a higher rate of maternal psychiatric disorders in mothers without a previous disorder (Fairthorne et al. 2015a). The second (Morgan et al. 2012) identified that the children of mothers with chronic schizophrenia, bipolar disorder or unipolar major depression had a higher rate of ID in their children compared to the children of unaffected mothers.

Similarly, mothers of children with ASD had a higher rate of a range of psychiatric disorders but here studies providing a high level of evidence are more plentiful. One research group (Fairthorne et al. 2015b) estimated the burden of care in mothers of children with ASD compared to other mothers by looking only at mothers with no psychiatric history before the birth of their child. They identified that this subset of mothers of children with ASD had a higher rate of treatments for psychiatric disorders (and hence a higher estimated burden of care) after the birth of their child than other mothers. Another (Daniels et al. 2008) examined the diagnoses associated with hospitalisations in mothers of a child with ASD. Mothers of a child with ASD were more likely to have been hospitalised with an associated diagnosis of depression, personality disorders or schizophrenia than mothers of children without ASD. Three more studies used data linkage and reported that parents of a child with ASD were more likely to have been diagnosed with schizophrenia spectrum disorders (Sullivan et al. 2012, Jokiranta et al. 2013), affective disorders (Jokiranta et al. 2013), bipolar disorders (Sullivan et al. 2012) or personality disorders (Mouridsen et al. 2007) than parents of children without ASD. An earlier Danish study (Larsson et al. 2005) found that pre-existing parental psychiatric disorders were associated with increased rates of ASD in the offspring.

Less strong evidence of higher rates of psychiatric disorders in families and parents of a child with ASD were provided by two other research groups (Bolton et al. 1998, Singhi et al. 1990). An examination of psychiatric disorders in the family of probands with ASD compared to those with Down syndrome, revealed that the families of the probands with ASD had significantly more obsessive-compulsive 
and affective disorders than the families of probands with Down syndrome (Bolton et al. 1998). In the second study, researchers interviewed parents of a child with ID and parents of only healthy children. Case parents were assessed as having significantly higher levels of neuroticism than control mothers (Sing hi et al. 1990).

Only one study (Emerson 2003) reported no difference between the psychiatric health of mothers of children with ID or ASD and other mothers. In this study, a secondary analysis of data collected from a British National Survey of nearly 10,000 mother-child dyads used a validated assessment to measure maternal well-being. The 245 mothers of children with ID had a slightly lower self-reported rate of psychiatric disorders than other mothers (Emerson 2003). Besides providing a lower level of assessed evidence than the previous data linkage studies (Table 1), data were self-reported psychiatric disorders. Mothers with more severe psychiatric disorders would have been less likely to participate since they might not have responded to invitations for inclusion or well enough to self-report. In summary, research suggests that mothers of children with ID or ASD have poorer psychiatric health than mothers of children without these disorders.

\section{Other aspects of mental health}

As with psychiatric disorders, the majority of other research on mental health in the carers of children with ID or ASD found that carer health was compromised. For example, one study (Caldwell 2008) used the SF-36 and provided strong evidence (Table 1) that both middle- aged and older women caring for adult relatives with developmental disabilities had poorer self-reported mental health compared to population norms. At lower levels of evidence, three studies (Gupta 2007, Harvey, O'Callaghan, and Vines 1997, Veisson 1999) concluded that parents of children with ID or ASD had more impaired health. In the first (Gupta 2007) reported that these parents had higher scores on a stress index than the parents of typically developing children. The second (Harvey, O'Callaghan, and Vines 1997) used the Beck Depression Inventory and found that mothers of children with developmental delay exhibited more depression than mothers of children without these disabilities. A third study (Veisson 1999) also used this inventory and parents, particularly mothers of disabled children, had more depressive symptoms than comparison parents (or mothers).

The conclusions of studies focusing on parents (or mothers) of children with ID were more varied than either the combined ID or ASD group or the homogenous ASD group. Using standardised stress scales, two independent research groups (Gallagher and Whiteley 2013, Browne and Bramston 1998) provided strong and moderate evidence (Table 1) of more stress in the parents of children with ID than in controls. Four other studies provided either strong or moderate levels of evidence (Table 1). Using the Beck Depression Inventory, Latina mothers of children with ID exhibited more depression than mothers of typically developing children (Blacher et al. 1997). In studies using the SF-12 or SF-36, mothers of children with Down syndrome exhibited poorer mental health than recognised population norms (Bourke et al. 2008, Hedov, Anneren, and Wikblad 2000). In a survey study, (Scott et 
al. 1997) researchers matched parents of an infant with Down syndrome to the parents of infants with no disability by SES and found that the Down syndrome group experienced more distress. By comparison, four studies, providing strong or moderate levels of evidence (Table 1) failed to find a difference between the maternal groups. Firstly, African American mothers of children with ID were assessed as being no more depressed than the mothers of typically developing children (Blacher et al. 1997). Another research group (Chen et al. 2001) used the SF-36 to survey mental health in middle-aged and older mothers of adults with ID and found no difference to population norms. The remaining two studies stratified by carer age. One study used the SF-12 to investigate the mental health of older parents caring for their children with ID (Llewellyn et al. 2010). Compared to population norms, mothers of children with ID aged 55 to 64 years reported poorer mental health but not the older parents (Llewellyn et al. 2010). Using similar methodology, middle-aged parents of children with ID and developmental disabilities did not differ from other parents in either self-reported depression levels or well-being (Seltzer et al. 2011). However, this had changed by their midsixties and those who remained caring for their child now reported higher levels of depressive symptoms(Seltzer et al. 2011).

Strong evidence (Table 1) was provided by a study (Lovell, Moss, and Wetherall 2012) which described that the parents of children with ASD had elevated concentrations of a pro- inflammatory biomarker for psychological distress. Moderate or mild evidence (Table 1) was provided by others studies in this area. Using survey methodology (Jeans et al.
2013), 200 mothers of children diagnosed with ASD and aged four years and nine months, exhibited higher levels of depression and stress than mothers of agematched children without ASD. In other case-control studies, also with data derived from surveys, parents (or mothers) of children with ASD reported more stress (Baker-Ericzén, Brookman-Frazee, and Stahmer 2005, Zablotsky, Bradshaw, and Stuart 2013, Montes and Halterman 2007), more aggravation(Schieve et al. 2011) and poorer mental health (Zablotsky, Bradshaw, and Stuart 2013, Montes and Halterman 2007) than other parents (or mothers). Other researchers identified greater stress in parents of children with ASD than in parents of typically developing children (Watt and Wagner 2012). Again using self-report, the psychological health of parents of a child with ASD was compromised compared to mainstream parents (Mugno et al. 2007). Similarly, others found that the selfreported mental health-related quality of life of carers of children with ASD was lower than population norms (Rizk, PizurBarnekow, and Darragh 2011). Notably, all of the studies with null results for mental health related to mothers of children with ID as opposed to ASD. This suggests that the mental health of mothers of children with ID might be less adversely affected than that of the mothers of children with ASD.

\subsubsection{Overall health and quality of life}

Within the broad category, Overall health and quality of life, all studies reported that parents of children with ID or ASD perceived lower levels than other parents. Without exception, studies reported lower levels of overall health and 
quality of life in parents of children with ID or ASD. Five studies provided mild or moderate evidence of a poorer overall health or quality of life of the mothers of children with ID. Two of these found that mothers of children with ID reported poorer well-being than other mothers (Norlin and Broberg 2013, Olsson and Hwang 2008). Likewise, others reported that families with a member with ID had a poorer quality of life (Browne and Bramston 1998) and poorer perceived overall health (Singhi et al. 1990) than the control group. Finally, another research group reported that the overall health of carers of children with Down syndrome was poorer than the comparator group (Hedov, Anneren, and Wikblad 2000).

One study provided strong evidence of a poorer self-perceived quality of life of parents of children with ASD. (Mugno et al. 2007). Other evidence was moderate or mild. For example, carers of children with ASD were found to have a worse perception of their quality of life and health-related quality of life (Khanna et al. 2011) than carers of children with no disability. In a similar way, a comparison of mothers of children with ASD to those with no disability found that case mothers had a larger proportion of days with negative health symptoms than the controls (Smith, Seltzer, and Greenberg 2012). Finally, comparisons of the parents of children with ASD without ID to parents of children without disabilities indicated a lower quality of life in the case parents (Lee et al. 2009).

\subsubsection{Summary}

In the vast majority of studies, poorer physical health was demonstrated in the mothers of children with ID or ASD compared to other mothers. Findings ranged from poorer overall physical health to a higher prevalence of specific conditions such as asthma, arthritis and diabetes. There was a similar picture with other aspects of mental health and quality of life. Mothers of children with ID or ASD most often had an increased prevalence of psychiatric disorders, more stress, depression and poorer overall mental health. Lastly, researchers consistently reported that mothers of children with ID or ASD had a lower perception of their quality of life than other mothers.

\subsection{Maternal comparisons by child disability}

In many instances, comparisons involved the health of mothers of children with ASD and the mothers of children with Down syndrome. Other comparisons involved the mothers of children with ID but not Down syndrome to mothers of children with Down syndrome. All reports described that the mothers of children with ASD had the poorest outcomes of all maternal groups and mothers of children with Down syndrome the next best after mothers of typically developing children.

When looking at intergroup comparisons, it is important to consider the possibility of confounding since sociodemographic variables are not randomly distributed among disability groups (Leonard et al. 2011). Two examples which provide a mild level of evidence of such confounding pertain to mothers of children with Down syndrome. The first study (Stoneman 2007) compared the parents of children with Down syndrome to the parents of children with ID of other aetiologies. Before adjusting for income 
level, the well-being of the Down syndrome group was higher. After adjustment, this advantage disappeared. Likewise, after adjusting for SES, researchers (Stores et al. 1998) concluded that the mothers of the children with Down syndrome were less stressed than the mothers of children with other forms of ID. This difference was not apparent before adjustment.

All but one study (Totsika, Hastings, Emerson, Lancaster, et al. 2011) provided a mild level of evidence. An analysis of survey data (Olsson and Hwang 2008) indicated that mothers of children with ID had poorer well-being than mothers of children without ID and differences in economic hardship were a major risk factor. Compared to parents of children with other disabilities (Griffith et al. 2010, Dumas et al. 1991, Sanders and Morgan 1997), parents of children with Down syndrome had less-self-reported stress. In another case-control study, (Lenhard et al. 2005) mothers of children with ID of unknown cause had more anxiety, guilt and emotional burden than the mothers of children with Down syndrome. Further, the Down syndrome group was indistinguishable from the mothers of typically developing children (Lenhard et al. 2005). Notably, none of these studies adjusted for SES and this may have confounded the results.

Other comparisons involved different aspects of mental health. For example, using questionnaires, authors (Hamlyn-Wright, Draghi-Lorenz, and Ellis 2007, Piven et al. 1991) reported lower levels of anxiety and depression in the parents of children with Down syndrome than in the parents of children with ASD. In the first study (Hamlyn-Wright, DraghiLorenz, and Ellis 2007), the authors commented that the parents of children with ASD were of higher SES than the Down syndrome group but nevertheless did not account for this in their analysis. In a third study (Estes et al. 2009), using validated stress and psychological distress measures, mothers of children with ASD exhibited higher levels than mothers of children with developmental delay without ASD. Another study used the Beck Depression Inventory to compare the levels of depression in mothers of children with ASD to those of children with ID without ASD (Olsson and Hwang 2001). In an attempt to adjust for SES, groups were matched according to geographical area of residence. The mothers of children with ASD displayed more severe depression than the mothers of children with ID but not ASD (Olsson and Hwang 2001).

Three studies compared aspects of the mental health of parents of children with ASD with and without ID using a validated questionnaire. Parents of children with ASD without ID demonstrated a lower quality of life and more stress than the parents of children with ASD with ID. Mothers of five year old children with ASD without ID reported higher levels of maternal emotional disorder than the mothers of children with ASD with ID (Totsika, Hastings, Emerson, Berridge, et al. 2011). Whilst the higher level of emotional disorder in the mothers of children with ASD without ID may reflect a higher burden of care it could also be indicative of a greater pre-disposition to mental health problems. The same research group looked at emotional disorder in the mothers of children with ASD with and without ID in children from 5 to 16 years old and found no difference between the two ASD groups but higher levels in the ASD group than in the mothers of children 
with ID only (Totsika, Hastings, Emerson, Lancaster, et al. 2011).

Research suggested that the burden of care-giving had least effect (if the reported associations are causal) on the health of the parents of children with Down syndrome (Lenhard et al. 2005, Stores et al. 1998, Hamlyn-Wright, Draghi-Lorenz, and Ellis 2007, Piven et al. 1991, Griffith et al. 2010, Dumas et al. 1991, Eisenhower, Baker, and Blacher 2005, Sanders and Morgan 1997, Fairthorne et al. 2015a) Most often, second least affected group was the parents of children with others forms of ID (Estes et al. 2009, Olsson and Hwang 2001). The parents of children with ASD were most often assessed as having the poorest health (Olsson and Hwang 2001, Totsika, Hastings, Emerson, Lancaster, et al. 2011, Fairthorne et al. 2014) and particularly those parents of a child with ASD without ID (Mugno et al. 2007, Totsika, Hastings, Emerson, Berridge, et al. 2011, Fairthorne et al. 2015b) (Figure 2).

Figure 2: Maternal health rankings by the disability group of her child as suggested by the core review

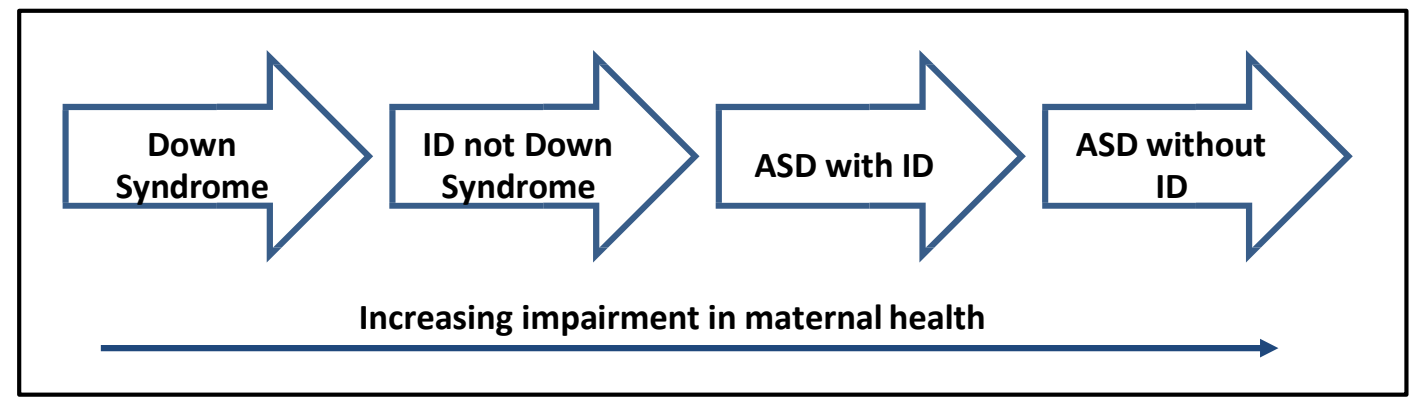

ID, intellectual disability; ASD, autism spectrum disorder

\section{EXPLANATIONS AND IMPLICATIONS}

\subsection{Explaining intergroup disparities}

Mothers caring for children with ASD were most often described as having poorer health and mothers of children with Down syndrome better health in comparison to other mothers of children with ID or ASD. The health of mothers associated with other diagnostic groups appeared to lie somewhere in between (Figure 2). Some research might explain these discrepancies. For example, in a comparison of children with Down syndrome and those with ASD, researchers demonstrated that the children with Down syndrome had more social competence and less problem behaviours than those with ASD (Griffith et al. 2010). Others reported more severe behavioural and emotional problems in children with ASD than in those with ID (Totsika, Hastings, Emerson, Lancaster, et al. 2011). Another research group suggested that the mothers of children with Down syndrome feel as rewarded by their children as mothers of children without disabilities (Hodapp et al. 2001) whilst others found that these mothers were more rewarded than the parents of children with other developmental disabilities (Corrice and Glidden 2009). In other words, the associations of maternal health with child behaviour and rewards previously described might explain some of our 
preliminary rankings of poorer maternal health. Compared to controls, parents of a child with ID reported lower levels of social support (Gallagher and Whiteley 2013). In a similar way, the existence of diagnostic issues for their child and their own personality traits might also contribute to the poorer health of mothers of children with ASD.

\subsection{Implications of this review}

Mothers of children with ASD without ID were identified as having impaired health. Further research into the correlates of poorer health in these mothers is implicated so that informed supports and interventions can be developed to assist these mothers to improve their health. Furthermore, the stronger correlates with poorer health in mothers of children with ID or ASD provide valuable information for services and interventions with the aim of assisting mothers to improve their health. Similarly, providing more support, such as home services, for mothers with health issues, might make the way for their improved health. A review of the correlates of poorer health in these mothers of children would provide informed direction for the development of this support. 


\section{REFERENCES}

Allik, H, J-O Larsson, and $\mathrm{H}$ Smedje. 2006. "Health-related quality of life in parents of school-age children with Asperger syndrome or high-functioning autism." Health and Quality of Life Ourcomes 4 (1). doi: 10.1186/1477-75254-1.

American Psychiatric Association. 2013. The Diagnostic and Statistical Manual of Mental Disorders: DSM 5. Arlington, VA: BookpointUS.

Baker-Ericzén, M, L BrookmanFrazee, and A Stahmer. 2005. "Stress levels and adaptability in parents of toddlers with and without autism spectrum disorders." Research and Practice for Persons with Severe Disabilities 30 (4):194-204.

Blacher, J, S Lopez, J Shapiro, and J Fusco. 1997. "Contributions to depression in Latina mothers with and without children with retardation: implications for caregiving." Family Relations 46 (4):325-34.

Bolton, P, A Pickles, M Murphy, and M Rutter. 1998. "Autism, affective and other psychiatric disorders: patterns of familial aggregation." Psychological Medicine 28 (2):385-95.

Bourke, J, B Ricciardo, A Bebbington, K Aiberti, P Jacoby, P Dyke, M Msall, C Bower, and H Leonard. 2008. "Physical and mental health in mothers of children with Down syndrome." Journal $\begin{array}{llll}\text { of Pediatrics } 153 & \text { (3):320-6. doi: }\end{array}$ 10.1016/j.jpeds.2008.02.047.

Browne, G, and P Bramston. 1996. "Quality of life in the families of young people with intellectual disabilities." Australian and New Zealand Journal of Mental Health Nursing 5 (3):120.
Browne, G, and P Bramston. 1998. "Stress and the quality of life in the parents of young people with intellectual disabilities." Journal of Psychiatric and Mental Health Nursing 5 (5):415-21. doi: 10.1046/j.1365-2850.1998.00154.x.

Button, K, J Ioannidis, C Mokrysz, B Nosek, J Flint, E Robinson, and M Munafo. 2013. "Power failure: why small sample size undermines the reliability of neuroscience." Nature Reviews Neuroscience 14 (5):365-376. doi: 10.1038/nrn3475.

Caldwell, J. 2008. "Health and access to health care of female family caregivers of adults with developmental disabilities." Journal of Disability Policy

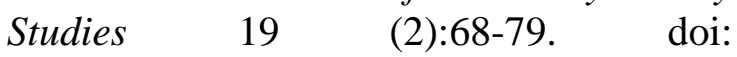
10.1177/1044207308316093.

Cantwell, J, O Muldoon, and S Gallagher. 2014. "Social support and mastery influence the association between stress and poor physical health in parents caring for children with developmental disabilities." Research in Developmental Disabilities 35 (9):2215- 2223. doi: 10.1016/j.ridd.2014.05.012.

Chen, S, Ryan H, T Heller, and E Chen. 2001. "Health status of mothers of adults with intellectual disability." Journal of Intellectual Disability Research 45 (5):439-49. doi: 10.1046/j.13652788.2001.00352.x.

Corrice, A , and L Glidden. 2009. "The Down syndrome advantage: fact or fiction?" American Journal on Intellectual and Developmental Disabilities 114 (4):254-68 doi: 10.1352/1944-7558114.4.254-268

Daniels, J, U Forssen, C Hultman, S Cnattingius, D Savitz, M Feychting, and P Sparen. 2008. "Parental psychiatric disorders associated with autism spectrum disorders in the offspring." Pediatrics 121 
(5):1357-62. doi: 10.1542/peds.2007-2296.

Dumas, J, L Wolf, S Fisman, and A Culligan. 1991. "Parenting stress, child behavior problems, and dysphoria in parents of children with autism, Down syndrome, behavior disorders, and normal development." Exceptionality 2 (2):97-110. doi: 10.1080/09362839109524770.

Eisenhower, A, B Baker, and $\mathrm{J}$ Blacher. 2005. "Preschool children with intellectual disability: syndrome specificity, behaviour problems and maternal well-being." Journal of Intellectual Disability Research 49 (9):657-71. doi: 10.1111/j.13652788.2005.00699.x.

Eisenhower, A, B Baker, and $\mathrm{J}$ Blacher. 2009. "Children's delayed development and behavior problems: impact on mothers' perceived physical health across early childhood." Social Science and Medicine 68 (1):89-99. doi: 10.1016/j.socscimed.2008.09.033.

Eisenhower, A, J Blacher, and B Baker. 2013. "Mothers' perceived physical health during early and middle childhood: relations with child developmental delay and behavior problems." Research in Developmental Disabilities 34 (3):105968. doi: 10.1016/j.ridd.2012.12.002.

Emerson, E. 2003. "Mothers of children and adolescents with intellectual disability: social and economic situation, mental health status, and the self-assessed social and psychological impact of the child's difficulties." Journal of Intellectual Disability Research 47 (4-5):385-99. doi: 10.1046/j.1365-2788.2003.00498.x.

Estes, A, J Munson, G Dawson, E Koehler, XH Zhou, and R Abbott. 2009. "Parenting stress and psychological functioning among mothers of preschool children with autism and developmental delay." Autism 13 (4):375-87. doi:
$10.1177 / 1362361309105658$.

Fairthorne, J , P Jacoby, J Bourke, $\mathrm{N}$ de Klerk, and H Leonard. 2015a. "Onset of maternal psychiatric disorders after the birth of a child with intellectual disability: a retrospective cohort study." Journal of Psychiatry Research 61 223-230. doi: 10.1016/j.jpsychires.2014.11.011.

Fairthorne, J , P Jacoby, J Bourke, $\mathrm{N}$ de Klerk, and H Leonard. 2015b. "Onset of maternal psychiatric disorders after the birth of a child with autism spectrum disorder: a retrospective cohort study." Autism. doi: 1362361314566048.

Fairthorne, J, G Hammond, J Bourke, P Jacoby, and H Leonard. 2014. "Early mortality and primary causes of death in mothers of children with intellectual disability or autism spectrum disorder: a retrospective cohort study." Plos One 9 (12). doi: 10.1371/journal.pone.0113430.

Gallagher, S, A Phillips, M Drayson, and D Carroll. 2009. "Caregiving for children with developmental disabilities is associated with a poor antibody response to influenza vaccination." Psychosomatic Medicine $71 \quad$ (3):341-4. doi: 10.1097/PSY.0b013e31819d1910.

Gallagher, S, and J Whiteley. 2013. "The association between stress and physical health problems in parents caring for children with intellectual disabilities is moderated by children's challenging behaviours." Journal of Health Psychology 18 (9):1220-1231. doi: $10.1177 / 1359105312464672$.

Griffith, G, R Hastings, S Nash, and $\mathrm{C}$ Hill. 2010. "Using matched groups to explore child behavior problems and maternal well-being in children with Down syndrome and autism." Journal of Autism and Developmental Disorders 40 (5):6109. doi: 10.1007/s10803-009-0906-1. 
Gupta, V. 2007. "Comparison of parenting stress in different developmental disabilities." Journal of Developmental and Physical Disabilities 19 (4):417-25. doi: 10.1007/s10882-007-9060-x.

Hamlyn-Wright, S, R DraghiLorenz, and J Ellis. 2007. "Locus of control fails to mediate between stress and anxiety and depression in parents of children with a developmental disorder." Autism 11 (6):489-501. doi: $10.1177 / 1362361307083258$.

Harvey, J, M O'Callaghan, and B Vines. 1997. "Prevalence of maternal depression and its relationship to ADL skills in children with developmental delay." Journal of Paediatrics and Child Health 33 (1):42-6. doi: 10.1111/j.14401754.1997.tb00989.x.

Hedov, G, G Anneren, and $\mathrm{K}$ Wikblad. 2000. "Self-perceived health in Swedish parents of children with Down's syndrome." Quality of Life Research 9 (4):415-22. doi: 10.1023/A:1008910527481.

Hodapp, R, T Ly, D Fidler, and L Ricci. 2001. "Less stress, more rewarding: parenting children with Down syndrome." Parenting 1 (4):317-37. doi: 10.1207/S15327922PAR0104_3.

Jeans, L, R Santos, D Laxman, B McBride, and W Dyer. 2013. "Examining ECLS-B: maternal stress and depressive symptoms when raising children with ASD." Topics in Early Childhood Special Education 33 (3):162-171. doi: 10.1177/0271121413481680.

Jokiranta, E, A Brown, M Heinimaa, K Cheslack-Postava, A Suominen, and A Sourander. 2013. "Parental psychiatric disorders and autism spectrum disorders." Psychiatry Research 207 (3):203-211. doi: 10.1016/j.psychres.2013.01.005.
Kelso, Tara, Davina French, and Miguel Fernandez. 2005. "Stress and coping in primary caregivers of children with a disability: a qualitative study using the Lazarus and Folkman Process Model of Coping." Journal of Research in Special Educational Needs 5 (1):3-10. doi: 10.1111/j.1471-3802.2005.00033.x.

Khanna, R, S Madhavan, M Smith, J Patrick, C Tworek, and B Becker-Cottrill. 2011. "Assessment of health-related quality of life among primary caregivers of children with autism spectrum disorders." Journal of Autism and Developmental Disorders $41 \quad$ (9):1214-27. doi: 10.1007/s10803-010-1140-6.

Lach, L, D Kohen, R Garner, J Brehaut, A Miller, A Klassen, and $\mathrm{P}$ Rosenbaum. 2009. "The health and psychosocial functioning of caregivers of children with neurodevelopmental disorders." Disability and Rehabilitation 31 (9):741-52. doi: $10.1080 / 09638280802242163$.

Larsson, H, W Eaton, K Madsen, M Vestergaard, A Olesen, E Agerbo, D Schendel, $\mathrm{P}$ Thorsen, and $\mathrm{P}$ Mortensen. 2005. "Risk factors for autism: perinatal factors, parental psychiatric history, and socioeconomic status." American Journal of Epidemiology 161 (10):916-25. doi: 10.1093/aje/kwi123.

Lee, C, C. Lopata, M Volker, M Thomeer, R Nida, J Toomey, S Chow, and A Smerbeck. 2009. "Health-related quality of life of parents of children with highfunctioning autism spectrum disorders." Focus on Autism and Other Developmental Disabilities 24 (4):227-239. doi: $10.1177 / 1088357609347371$.

Lenhard, W, E Breitenbach, H Ebert, H Schindelhauer-Deutscher, and W Henn. 2005. "Psychological benefit of diagnostic certainty for mothers of children with disabilities: lessons from Down 
syndrome." American Journal of Medical Genetics 133A:170-5. doi: 10.1002/ajmg.a.30571.

Leonard, H, E Glasson, N Nassar, A Whitehouse, A Bebbington, J Bourke, P Jacoby, G Dixon, E Malacova, C Bower, and F Stanley. 2011. "Autism and intellectual disability are differentially related to sociodemographic background at birth." PLoS ONE 6 (3):e17875.

Llewellyn, G, D McConnell, L Gething, R Cant, and H Kendig. 2010. "Health status and coping strategies among older parent-carers of adults with intellectual disabilities in an Australian sample." Research in Developmental Disabilities 31 (6):1176-86. doi: 10.1016/j.ridd.2010.08.003.

Lovell, B, M. Moss, and M Wetherall. 2012. "The psychosocial, endocrine and immune consequences of caring for a child with autism or ADHD." Psychoneuroendocrinology 37 (4):534-42. doi: 10.1016/j.psyneuen.2011.08.003.

Magaña, S, and M Smith. 2006. "Health outcomes of midlife and older Latina and Black American mothers of children with developmental disabilities." Mental Retardation 44 (3):224-34. doi: 10.1352/0047-

6765(2006)44[224:HOOMAO]2.0.CO;2.

McStay, R, D Trembath, and C Dissanayake. 2014. "Stress and family quality of life in parents of children with autism spectrum disorder: parent gender and the double ABCX model." Journal of Autism and Developmental Disorders:118. doi: 10.1007/s10803-014-2178-7.

Montes, G, and J Halterman. 2007. "Psychological functioning and coping among mothers of children with autism: a population-based study." Pediatrics 119 (5):1040-6. doi: 10.1542/peds.2006-2819.
Morgan, V, M. Croft, G Valuri, S Zubrick, $\mathrm{C}$ Bower, $\mathrm{T}$ McNeil, and $\mathrm{A}$ Jablensky. 2012. "Intellectual disability and other neuropsychiatric outcomes in high-risk children of mothers with schizophrenia, bipolar disorder and unipolar major depression." British Journal of Psychiatry 205 (4):282-289. doi: 10.1192/bjp.bp.111.093070.

Mouridsen, S, B Rich, T Isager, and N Nedergaard. 2007. "Psychiatric disorders in the parents of individuals with infantile autism: a case-control study." Psychopathology 40 (3):166-71. doi: 10.1159/000100006.

Mugno, D, L Ruta, V D’Arrigo, and L Mazzone. 2007. "Impairment of quality of life in parents of children and adolescents with pervasive developmental disorder." Health and Quality of Life Ourcomes 5:22. doi: 10.1186/1477-75255-22.

Norlin, D, and M Broberg. 2013. "Parents of children with and without intellectual disability: couple relationship and individual well-being." Journal of Intellectual Disability Research 57 (6):552-566. doi: 10.1111/j.13652788.2012.01564.x.

Olsson, M, and C Hwang. 2001. "Depression in mothers and fathers of children with intellectual disability." Journal of Intellectual Disability Research 45 (6):535-43. doi: 10.1046/j.13652788.2001.00372.x.

Olsson, M, and C Hwang. 2008. "Socioeconomic and psychological variables as risk and protective factors for parental well-being in families of children with intellectual disabilities." Journal of Intellectual Disability Research 52 (12):1102-13. doi: 10.1111/j.13652788.2008.01081.x.

Piven, J, G Chase, R Landa, M 
Wzorek, J Gayle, D Cloud, and S Folstein. 1991. "Psychiatric disorders in the parents of autistic individuals." Journal of the American Academy of Child and Adolescent Psychiatry 30 (3):471-8. doi: 10.1097/00004583-199105000- 00019.

Rizk, S, K Pizur-Barnekow, and A Darragh. 2011. "Leisure and social participation and health-related quality of life in caregivers of children with autism." Occupation, Participation and Health 31 (4):164-71. doi: 10.3928/1539449220110415-01.

Sanders, J, and S Morgan. 1997. "Family stress and adjustment as perceived by parents of children with autism or Down syndrome: implications for intervention." Child and Family Behavior Therapy 19 (4):15-32. doi: 10.1300/J019v19n04_02.

Schieve, L, S Boulet, M Kogan, M Yeargin-Allsopp, C Boyle, S Visser, S Blumberg, and C Rice. 2011. "Parenting aggravation and autism spectrum disorders: 2007 National Survey of Children's Health." Disability and Health Journal 4 (3):143-152. doi: 10.1016/J.DHJO.2010.09.002.

Scott, B, L Atkinson, H Minton, and $\mathrm{T}$ Bowman. 1997. "Psychological distress of parents of infants with Down syndrome." American Journal on Mental Retardation $102 \quad$ (2):161-71. doi: 1352/0895-

8017\%281997\%29102\%3C0161\%3APDO POI\%3E2.0.CO\%3B2.

Seltzer, M, F Floyd, J Song, J Greenberg, and J Hong. 2011. "Midlife and aging parents of adults with intellectual and developmental disabilities: impacts of lifelong parenting." American Journal on Intellectual and Developmental Disabilities $116 \quad$ (6):479-99. doi: 10.1352/1944-7558-116.6.479.

Singhi, P, L Goyal, D Pershad, S
Singhi, and B Walia. 1990. "Psychosocial problems in families of disabled children." British Journal of Medical Psychology 63 (2):173-82 . doi: 10.1111/j.20448341.1990.tb01610.x.

Smith, L, M Seltzer, and J Greenberg. 2012. "Daily health symptoms of mothers of adolescents and adults with Fragile $\mathrm{X}$ syndrome and mothers of adolescents and adults with autism spectrum disorder." Journal of Autism and Developmental Disorders 42 (9):18361846. doi: 10.1007\%2Fs10803-011-14227.

Stoneman, Z. 2007. "Examining the Down syndrome advantage: mothers and fathers of young children with disabilities." Journal of Intellectual Disability Research 51 (12):1006-17. doi: 10.1111/j.13652788.2007.01012.x.

Stores, R, G Stores, B Fellows, and S Buckley. 1998. "Daytime behaviour problems and maternal stress in children with Down's syndrome, their siblings, and non- intellectually disabled and other intellectually disabled peers." Journal of Intellectual Disability Research 42 (3):228-37. doi: 10.1046/j.13652788.1998.00123.x.

Sullivan, P, C Magnusson, A Reichenberg, M Boman, C Dalman, M Davidson, E Fruchter, C Hultman, M Lundberg, and N Långström. 2012. "Family history of schizophrenia and bipolar disorder as risk factors for autism." Archives of General Psychiatry 2:1-5. doi: 10.1001/archgenpsychiatry.2012.730.

Totsika, V, R Hastings, E Emerson, D Berridge, and G Lancaster. 2011. "Behavior problems at 5 years of age and maternal mental health in autism and intellectual disability." Journal of Abnormal Child Psychology 39 (8):113747. doi: 10.1007/s10802-011- 9534-2. 
Totsika, V, R Hastings, E Emerson, G Lancaster, and D Berridge. 2011. "A population-based investigation of behavioural and emotional problems and maternal mental health: associations with autism spectrum disorder and intellectual disability." Journal of Child Psychology and Psychiatry 52 (1):91-9. doi: 10.1111/j.1469- 7610.2010.02295.x.

Veisson, M. 1999. "Depression symptoms and emotional states in parents of disabled and non-disabled children." Social Behavior and Personality 27 (1):8798. doi: 10.2224/sbp.1999.27.1.87.

Watt, M, and S Wagner. 2012. "Parenting a child with autism spectrum disorder: parental work context." Community, Work and Family 16 (1):1-19. doi: 10.1080/13668803.2012.692890.

Werner, S., and C. Shulman. 2014. "Does type of disability make a difference in affiliate stigma among family caregivers of individuals with autism, intellectual disability or physical disability?" Journal of Intellectual Disability Research. doi: 10.1111/jir.12136.

Yamaki, K, K Hsieh, and T Heller. 2009. "Health profile of aging family caregivers supporting adults with intellectual and developmental disabilities at home." Journal of Intellectual and Developmental Disabilities 47 (6):273-84. doi: 10.1352/1934- 9556-47.6.425.

Zablotsky, B, C Bradshaw, and E Stuart. 2013. "The association between mental health, stress, and coping supports in mothers of children with autism spectrum disorders." Journal of Autism and Developmental Disorders 43 (6):1380-93. doi: 10.1007/s10803-012-1693-7. 